\section{PRECISION FOR IMPLANTS}

The Surgic XT Plus from NSK, now with an LED micromotor, brings a new dimension of control through the innovative application of Advanced Torque Calibration (ATC). ATC ensures that you are always working with the optimum torque and speed settings for accurate, safe and smooth operation.

VarioSurg delivers strong, precise cutting power when you need it most. This ultrasonic approach to surgery reduces heat generation and minimises osteonecrosis. This is enhanced by TiN (Titanium Nitride) coated bone cutting tips, that increase cutting efficiency and leave a sharp surface that aids bone formation.

Both Surgic XT Plus and VarioSurg benefit from NSK's revolutionary cellular glass optics, delivering 20\% brighter illumination to the treatment area.

The iSD900 cordless prosthodontic implant screwdriver also features NSK's unique Torque Calibration System (TCS) which ensures that the correct torque is applied at all times. This helps the clinician to screw and unscrew abutments reliably and without risk, eliminating tiring and strenuous manual procedures.

Reader response number 56

\section{LOW VISCOSITY FLOWABLE COMPOSITE}

Permanent retention is the only way to ensure long-term stability of orthodontic treatment and more and more dentists have found that StarFlow from Danville Materials is the perfect solution for permanent wire retention.

Bonding retainer wires can be an intricate procedure especially on vertical tooth surfaces, but StarFlow makes easy work of it. This super low viscosity flowable composite resists slumping and gravitational forces, staying in place until you are ready to permanently light-cure your retention.

\section{COST-EFFECTIVE RESTORATIVE}

Venus Bulk Fill from Heraeus is an advanced low-stress flowable posterior restorative. It provides dentists with a faster, easier technique than incremental layering in deep cavities (up to $4 \mathrm{~mm}$ ). The material is ideal for use in class I and II direct restorations or as a cavity lining under direct restorative materials. The results include a reduction in chairside time and a more costeffective restoration.

Venus Bulk Fill has:

- Low shrinkage stress

- Flowable self-adaptive handling

- Easy placement technique (in up to 4 $\mathrm{mm}$ increments).
Available in $5 \mathrm{~g}$ and $1 \mathrm{~g}$ single patient use syringes, StarFlow also provides long-term fluoride release and has the highest compressive strength of any flowable composite available, so it's unlikely to break or shear once placed.

\section{Reader response number 57}

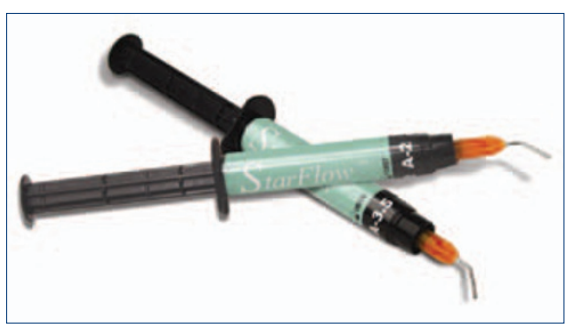

Compared with other bulk fill materials, the new Heraeus composite has a long working time. But, it is quick and simple to use, in just three easy steps. Venus Bulk Fill is highly radiopaque and compatible with methacrylate bonding adhesives. The product is available in syringes and pre-loaded tubes (PLTs). Reader response number 58

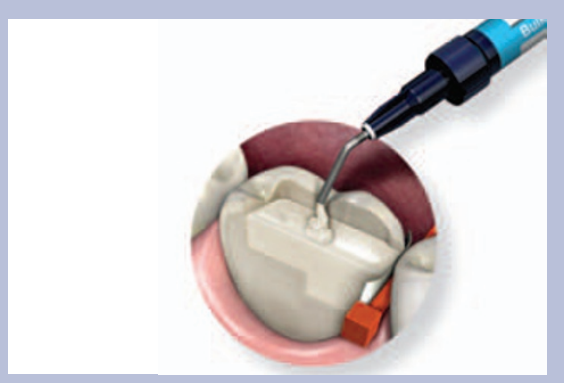

